\title{
ANÁLISE CRÍTICA DOS FUNDAMENTOS TEÓRICOS DA EDUCAÇÃO INCLUSIVA
}

\section{Analyse critique des fondements théoriques de l'éducation d'inclusion.}

\author{
Lindomar Wessler Boneti ${ }^{1}$
}

\section{Resumo}

Trata-se de uma análise crítica dos fundamentos teóricos e conceituais que sustentam o discurso da "educação inclusiva", discutindo os conceitos chaves envolvidos na formulação deste discurso, como é o caso da exclusão, da cidadania, da desigualdade e da diferença, na perspectiva de se diferenciar tipos de ações educacionais que produzem mesmo o que se poderia chamar de "inclusão social", de atividades que assim são denominadas, mas que na verdade se resumem em meros procedimentos burocráticos. Argumenta-se, neste texto, que, em geral, as instituições públicas não absorveram a evolução conceitual e teórica processadas na academia em relação a significações envolvidas no discurso da "educação inclusiva", carecendo de revisões.

Palavras-chave: Educação; Inclusão; Desigualdade; Cidadania.

\section{Résumé}

L' objet de ce texte est, construire les bases conceptuelles et théoriques qui soutiennent le discours de " l' éducation d' inclusion " à partir de la discution des concepts clés adoptés dans la formulation de ce discours, comme le cas de l' exclusion, de la citoyennété, de l' inégalité et de la différance, dans la perspective de se différencier les types d'actions éducationnelles qui produisent ce qu' on peut appeller de "l' inclusion sociale ", d' activités qui sont ainsi nomées, mais que dans la vérité, deviennent des procédures burocratiques. On s' agit aussi, dans ce texte que, en général, les institutions publiques n' absorbent pas l' évolution conceptuelle et théorique élaborée dans l' académie par rapport aux significations adoptées dans le discours de " l 'éducation d' inclusion ", de manière qu' on aperçoit la manque de révision.

Mots-clefs: Éducation; Inclusion; Inégalité; Citoyenneté.

Doutor (Ph.D.) em Sociologia, Professor do Programa de Pós-Graduação em Educação da Pontifícia Universidade Católica do Paraná - PUCPR. Correio Eletrônico: boneti.lindomar@pucpr.br 


\section{Introdução}

Nos dias de hoje, no Brasil, utiliza-se em demasia a expressão "educação inclusiva" em diferentes situações, ao se referir ao projeto de garantias do acesso a diversos grupos sociais, como é o caso do negro, ao ensino superior por meio das cotas, à "inclusão" de crianças portadoras de "deficiências" em escolas regulares e outras mais. Trata-se, na verdade, de um discurso que associa a ação educativa à "devolução" das condições de cidadania à pessoa, ou ao grupo social. Este discurso é fundamentado sobre algumas pressuposições, as quais geram tropeços conceituais e teóricos dignos de análises. O primeiro deles, o qual se pode considerar o pai de todos, refere-se à construção do raciocínio dicotômico do dentro e do fora, originando conceitos e formulações teóricas questionáveis. O objetivo deste texto, portanto, é o de analisar as bases conceituais e teóricas que fundamentam o discurso da "educação inclusiva", discutindo os conceitos chaves envolvidos na formulação deste discurso, como é o caso da exclusão, da cidadania, da desigualdade e da diferença, na perspectiva de se diferenciar tipos de ações educacionais que produzem mesmo o que se poderia chamar de "inclusão social", de atividades que assim são denominadas, mas que na verdade se resumem em meros procedimentos burocráticos. Argumenta-se, neste texto, que, em geral, as instituições públicas não absorveram a evolução conceitual e teórica processadas na academia em relação a significações envolvidas no discurso da "educação inclusiva", carecendo de revisões.

\section{A inclusão e a exclusão social}

Falar em termos de classes e de desigualdades, segundo Robert Castel (2003), é referir-se à concepção clássica da sociologia, que prevaleceu até meados da década de 70. De acordo com esta concepção, o coração da questão social é o conflito que opõe grupos sociais homogêneos em luta pela repartição dos benefícios do crescimento. A noção da exclusão social aparece mais tardiamente, com a crise da representação da questão social a partir da classe e da desigualdade social. Mas o aparecimento da noção da exclusão social não significou, necessariamente, a substituição da classe social e da desigualdade como representação da questão social.

Isto é, a noção da exclusão social aparece quando, no contexto social, tornou-se impossível a formalização do vínculo com a produção pela maioria da população, como outrora, quando se permitia a existência de grupos sociais homogêneos. Assim, a noção da exclusão social aparece exatamente no momento em que o sistema econômico quebra esta homogeneidade, im- 
pondo um processo de individualização. Neste caso, os "excluídos", segundo Robert Castel (2003), não constituem, a bem da verdade, de um grupo homogêneo. São mais precisamente coleções de indivíduos separados de seus pertencimentos coletivos, entregues a si próprios, e que acumulam a maior parte das desvantagens sociais: pobreza, falta de trabalho, sociabilidade restrita, condições precárias de moradia, grande exposição a todos os riscos de existência, etc. Portanto, ainda para o citado autor (2003), falar em exclusão social refere-se à inquietação geral diante da degradação das estruturas da sociedade salarial, sublinhando-se a necessidade de se ocupar das vítimas desta transformação. Portanto, para um bom entendimento, não se trata de considerar a exclusão social como uma categoria de análise, assim como é a da classe social, e sim de uma problemática social.

Esta interpretação atribuída à exclusão social exposta acima é atual e cultuada sobretudo pela academia francesa, em especial nas obras de Robert Castel (2003, 1996, 1997) e Serge Paugam (1999). Mas não foi sempre assim. O percurso da noção da exclusão social passou por uma trajetória histórica tortuosa, motivada por vários fatores. Em primeiro lugar, em decorrência da origem positivista da noção da exclusão social, partindo do pressuposto de dualidade e estaticidade das relações sociais. Assim, excluídas seriam as pessoas que estivessem fora do social, como os leprosos, os marginais, os doentes mentais etc. Trata-se de uma visão funcionalista de caracterizar um contingente populacional que estaria fora, à margem da sociedade, conforme se expressou René Lenoir, considerado o criador desta noção, no livro L’Exclus, publicado em 1974. Em segundo lugar, a própria origem positivista da noção de exclusão criou entraves na utilização desta noção na academia, em especial na brasileira, pela incompatibilidade do pressuposto de sociedade que esta noção trazia de sua origem com os estudos realizados pela academia crítica, em especial pelos marxistas, utilizando-se o referencial de classe. Em terceiro lugar, a trajetória histórica desta noção determinou o aparecimento de uma confusão metodológica a partir do entendimento de que a noção da exclusão social se constituísse de uma categoria de análise, assim como o de classe social. A partir de tal entendimento, seria incompatível falar ao mesmo tempo de classe e de exclusão social.

Assim, é possível se falar ainda em exclusão social, sobretudo se considerar a caminhada já realizada deste conceito na academia, adotando a significação dada pelos autores acima referidos. Neste caso, não significa incompatibilidade associar exclusão social, enquanto problemática social, e classe social, enquanto categoria de análise.

Mas com a noção de inclusão é diferente e apresenta maiores complicadores. Além de guardar consigo o significado original da exclusão, não se pode dizer que esta palavra se constitua de uma noção ou de um conceito. 
Trata-se de uma positivação em relação a uma problemática social, a da exclusão, segundo o entendimento original já considerado. Portanto, é mais um discurso que um conceito. Além desta pobre origem, agregou, durante a sua pequena história de vida, antigos ingredientes da política. O entendimento do social a partir de uma concepção dual do dentro e do fora já foi utilizada pelos contratualistas, em particular por Hobbes e Rousseau, fornecendo bases à sociologia política conservadora e ao direito. No seio desta concepção, umas das noções que nasceu e persiste até nossos dias é a noção de cidadania. A noção de cidadania que persiste nos dias atuais, e que conserva uma proximidade com a noção do ser incluído/a, é aquela associada aos direitos constitucionais. Em outras palavras, o entendimento do social a partir de uma concepção do dentro e do fora pode ter origem, antes de tudo, da noção de cidadania, ou de cidadão, a pessoa que estivesse "incluída" numa sociedade racional, numa sociedade de direito, numa sociedade de Estado (sociedade contratual). Com o advento da sociedade industrial e a complexidade inerente à urbanização, avolumou-se a dependência da sociedade civil frente às políticas sociais do Estado, quando esta interpretação dual de sociedade, entre os "incluídos" no contrato social e os "excluídos" dele, se ampliou ainda mais.

Nesta perspectiva, a pessoa "incluída" seria a pessoa juridicamente cidadã, isto é, com direitos e deveres frente ao contrato social, com direitos e deveres de votar e ser votado e usufruir dos direitos sociais básicos. Pode-se dizer que esta concepção de cidadania restringe o indivíduo a uma posição passiva na sociedade, isto porque se garante a participação do indivíduo por vias formais, na medida em que este indivíduo é "incluído" formalmente, juridicamente, como cidadão que vota, que tem opinião, que produz. Mas este entendimento de cidadania não atribui qualificativo de cidadania a uma pessoa que não vota, que não tem trabalho, que não opina. Utilizando-se um entendimento teórico do social como um todo, necessário se faz considerar cidadã também a pessoa pedinte de rua, aquela que não vota, que não trabalha e não opina formalmente. É preciso considerar que este tipo de população tem participação sim na sociedade, porque consome (e na sociedade capitalista o consumo é importante) e a sua presença se constitui de participação política. A participação política destas pessoas se faz exatamente pela exteriorização dos conflitos e problemas sociais.

Este conceito dual e jurídico de cidadania não apenas subsidiou o aparecimento do conceito de "inclusão" como estando dentro, mas também se constitui de objetivos do discurso da "educação inclusiva". Isto é, a partir de uma concepção conservadora de cidadania, atribui-se o "resgate à cidadania" a um procedimento burocrático de matrícula, por exemplo.

Em síntese, o conceito de inclusão carrega consigo dois pesos desfavoráveis: $\mathrm{O}$ primeiro deles diz respeito à sua herança teórica e metodológica 
utilizada para a sua formulação, o da dicotomização do dentro e do fora, coisa que a sua palavra-mãe, a exclusão, já superou ou, no mínimo, está em processo conforme visto em páginas anteriores neste trabalho. O segundo diz respeito à agregação de ingredientes conservadores da sociologia política, associando a inclusão à cidadania, enquanto condição de estar incluída no "contrato" social e, assim, usufruir de direitos. Ambas as situações fazem com que a palavra inclusão assuma uma significação da existência de um único projeto político de sociedade, o da classe dominante, reservando-se a esta classe o monopólio do controle do acesso aos serviços públicos, aos bens sociais, aos saberes, aos conhecimentos tecnológicos, à cultura etc.

\section{A Cidadania}

O entendimento do social a partir de uma concepção dual do dentro e do fora já foi utilizada pelos contratualistas, em particular Hobbes e Rousseau, fornecendo bases à sociologia política conservadora e ao direito. No seio desta concepção, umas das noções que nasceu e persiste até nossos dias é a noção de cidadania. A noção de cidadania que persiste nos nossos dias é aquela associada aos direitos constitucionais. Em outras palavras, o entendimento do social a partir de uma concepção do dentro e do fora pode ter origem, antes de tudo, da noção de cidadania, ou de cidadão, a pessoa que estivesse "incluída" numa sociedade racional, numa sociedade de direito, numa sociedade de Estado. Com o advento da sociedade industrial e a complexidade inerente à urbanização, avolumou-se a dependência da sociedade civil frente às políticas sociais do Estado, quando esta noção dual de sociedade, entre os "incluídos" no contrato social e os "excluídos" dele, se avolumou ainda mais.

Nesta perspectiva, a pessoa "incluída" seria a pessoa juridicamente cidadã, isto é, com direitos e deveres frente ao contrato social, com direitos e deveres de votar e ser votado e usufruir dos direitos sociais básicos. Não se pode dizer que esta concepção de cidadania restringe o indivíduo a uma posição passiva na sociedade, isto porque se garante a participação do indivíduo por vias formais, na medida em que este indivíduo é "incluído" formalmente, juridicamente, como cidadão que vota, que tem opinião, que produz. Mas este entendimento de cidadania não atribui qualificativo de cidadania a uma pessoa que não vota, que não tem trabalho, que não opina. Estas pessoas consideradas "não úteis" para a sociedade capitalista e produzidas por ela própria, passaram a ser chamadas de "excluídas". Se utilizarmos um entendimento teórico entendendo o social como um todo, necessário se faz considerar cidadã a pessoa pedinte de rua, aquela que não vota, que não trabalha e 
não opina formalmente. É preciso considerar que este tipo de população tem participação sim na sociedade, porque consome (e na sociedade capitalista o consumo é essencial) e a sua presença se constitui de participação política. A participação política destas pessoas se faz, sobretudo a partir dos conflitos sociais que geram. O fato de pedir esmola, o fato de não apresentar-se convenientemente conforme os hábitos convencionais, tudo isto é participar, é dizer que a sociedade está doente.

Este conceito dual e jurídico de cidadania não apenas subsidiou o aparecimento do conceito de "inclusão" como estando "dentro", mas também se constitui de objetivos do discurso da "educação inclusiva". Isto é, a partir de uma concepção conservadora de cidadania, atribui-se o "resgate à cidadania" a um procedimento burocrático de matrícula, por exemplo. Fala-se na verdade do resgate à plenitude da cidadania na medida em que se facilita o acesso a todas as pessoas ao saber socialmente construído, às habilidades profissionais, etc. Em síntese, todas as pessoas são cidadãs. Então, falar em inclusão como resgate da cidadania significa falar na busca da plenitude dos direitos sociais, da assistência social, da participação da pessoa em todos os aspectos da sociedade. A ação educativa, assim, seria "inclusiva" na medida em que proporciona a participação integral da pessoa na sociedade, sobretudo no sentido de fornecer elementos de autonomia individual, como é o caso da apropriação aos saberes para o trabalho, aos saberes culturais, da produção da cultura.

\section{A desigualdade e a Diferença}

O conceito de desigualdade também tem origens dos clássicos da sociologia política na medida em que a noção clássica de igualdade é associada ao acesso aos direitos sociais, de uma sociedade civil, organizada contratualmente. Rousseau (1991), na sua obra Discurso Sobre a Origem e os Fundamentos da Desigualdade entre Homens, carregando na conotação de valores morais, considera que ao falar de desigualdade, supõe-se a existência de faltas de direitos civis em virtude de uma relação de dominação (ou de opressão) de alguns segmentos sociais sobre outros, uma relação de exploração. O foco central da questão, segundo Rousseau, não é exatamente o sistema social, a estrutura social, mas o homem, a condição humana, a interpretação que o homem dá de si e dos outros após o aparecimento da sociedade civil.

Diferente de Rousseau, Marx ressalta a relação de integração entre o capital e o trabalho, assentada na desigualdade. Isso nos faz lembrar que, de fato, a teorização do modo de produção capitalista e, por que não dizer, da própria modernidade, feita por Marx, tem como base justamente o papel dia- 
lético da desigualdade. A desigualdade representa, no modo de produção capitalista, a integração e a desintegração, o fundamento da alienação do trabalhador e, conseqüentemente, a idéia da perpetuação da relação desigual, a base fundamental da luta de classe e o motor do conflito que propicia mudança. A desigualdade entre as pessoas proprietárias dos meios de produção e as da força de trabalho é fundamentada sobre a exploração de classe. Trata-se assim de uma relação desigual, assentada na exploração e, portanto, conflituosa. Trata-se de um conflito paradoxal: ambos os lados dependem um do outro para a sua perpetuação. Contudo, o significado histórico da desigualdade faz com que eles lutem pela eliminação da parte opositora.

Mesmo assim, a academia é historicamente contaminada pela visão contratual de igualdade/desigualdade, como se os direitos legais se constituíssem na principal fonte da igualdade entre as pessoas. Com o advento da modernidade e a complexidade trazida pela urbanização, esta noção ganha uma conotação nitidamente jurídica, acentuando a tônica do direito social. Como diz François Dubet (2001, p. 94), fazendo referência a Tocqueville: “...les sociétés modernes sont égalitaires dans la mesure où elles étendent le droit à l'égalité, notamment à l'égalité des chances, où, en termes normatifs et politiques, elles acceptent les inégalités tant quéelles n'empêchent pas les individus de concourir dans les épreuves de l'égalité des chances."

Esta noção de igualdade/desigualdade guarda uma conotação material do entendimento de condição social, fundamentada na relação que se estabelece entre a pessoa e a organização da sociedade civil, quem é, qual o papel exercido no grupo social, quanto ganha etc. A partir disso, estabelecemse os parâmetros utilizados pelas instituições para a delimitação da condição social, sem levar em consideração as interpretações historicamente construídas pela sociedade em relação à desigualdade.

\section{Os condicionantes do acesso no contexto das desigualdades sociais}

Considerando que a realidade social capitalista é caracterizada pelo contexto das desigualdades sociais, almeja-se pontuar questões de ordem teóricas e metodológicas implicadas na busca da compreensão dos principais fatores condicionantes ao acesso. Isto é, pressupõe-se que se tem uma complexidade teórica e metodológica para a compreensão dos limites do acesso. Não se tem a preocupação de esgotar o tema, mas no mínimo polemizá-lo.

No título, a palavra acesso vem de forma solta, o que cabe a pergunta: acesso a quê? Apesar do aparente generalismo, ao referir-se ao contexto social, esta palavra remete à construção de apenas um pressuposto: acesso aos bens culturais e sociais, ao capital cultural, econômico e público, aos 
saberes e habilidades necessárias à participação da atividade produtiva da sociedade etc.

O primeiro aspecto a se considerar no que diz respeito ao acesso é quanto ao método teórico utilizado para a compreensão dos fatores condicionantes do acesso. Costumeiramente o acesso tem sido tratado sob a ordem de uma dualidade metodológica e teórica entre o funcionalismo e o marxismo. O funcionalismo com o olhar das instituições enquanto resultado de um contrato social regulado pela lei que estaria a serviço de todos os segmentos sociais, interpreta o acesso como um processo que faz parte da dinâmica da funcionalidade do sistema, dependendo basicamente de dois fatores inter-relacionados: a maturidade institucional da sociedade e o desempenho da individualidade. Veja que à definição de instituição dada pelos funcionalistas cabe perfeitamente esta inter-relação, instituição é: conjunto de valores, crenças, normas, posições e papéis referentes a campos específicos de atividade e de necessidades humanas. A inter-relação destes dois campos é de mão dupla, isto é, o desempenho da individualidade está diretamente relacionada à maturidade institucional e vice-versa. Certamente que o evolucionismo social tem raízes nesta interpretação. Mas, para o marxismo, o acesso está condicionado à condição de classe, até mesmo o acesso às instituições estaria relacionado à condição de classe.

$\mathrm{Na}$ verdade, o acesso guarda uma complexidade volumosa de forma que fica complicado restringir a análise a partir de uma compreensão teórica, o que significa dizer que a verdadeira compreensão dos condicionamentos do acesso envolve questões metodológicas de como lidar a questão, a partir de que compreensão teórica ou de quais.

Neste sentido, seria de se considerar que para se buscar a compreensão de certas realidade sociais, como é o caso do acesso, é necessário se valer de diferentes compreensões teóricas, até mesmo as historicamente opostas, como é o caso do marxismo e do funcionalismo. Seria de comungar com a idéia do pensador canadense Guy Rocher (2004), da Universidade de Montreal, o qual expressou a necessidade da diversidade de compreensões e de modos de explicações de uma mesma realidade e que não há um só e bom conhecimento e explicação da realidade social. Nesse sentido, a complexidade que envolve o acesso, para compreender a verdadeira dinâmica dos seus condicionantes, é necessário valer-se de muitas contribuições teóricas, o que se busca fazer neste texto.

Após clarear as implicações metodológicas e teóricas na compreensão dos fatores condicionantes do acesso, trata-se aqui de pontuar os principais condicionantes relacionando-os às contribuições teóricas respectivas. Como se verá abaixo, todos os condicionamentos estão diretamente relacionados às desigualdades sociais. 
1. O primeiro condicionante do acesso, o que se pode dizer como sendo o primeiro fator de produção das desigualdades se dá ao nascer, no que se refere a: Gênero, Raça e Condição socioeconômica.

No entanto, Dubet (2003) alerta que existe diferenciação entre a pura igualdade real das condições de vida e os princípios da igualdade dos indivíduos. "Dito de outra forma, na modernidade os indivíduos são considerados como cada vez mais iguais e suas desigualdades empíricas não podem basearse nem no nascimento, nem na raça, nem na tradição", podendo os indivíduos se considerar fundamentalmente iguais e que se pode, legitimamente, reivindicar a igualdade de oportunidades e de direitos (DUBET, 2003, p. 24). Isto significa dizer que as sociedades modernas são igualitárias na medida em que elas estendem o direito à igualdade em termos normativos, jurídicos e políticos. Mas, na vida real, a desigualdade se apresenta ou se constrói na individualidade ou no coletivo. Ao nascer, a desigualdade ou a igualdade se apresentam ao indivíduo como fato consumado por mecanismos de pertencimentos, como o da classe social (ou casta, no caso da Índia), do gênero e o da etnia. A desigualdade ou a igualdade serem definidas no nascimento da individualidade se caracterizou mais nitidamente nas sociedades estamentais, próprias da Europa medieval. Mas, no capitalismo, a igualdade e a desigualdade continuam sendo definidas no nascimento do indivíduo, somando-se com os mecanismos de produção e de perpetuação destas condições sociais muito próprios deste modo de produção, como é o caso do mercado. Neste caso, a contribuição teórica que melhor explica a construção da desigualdade é a de Marx.

2. O segundo condicionante a se destacar está inserido na condição de classe e a apropriação dos frutos do trabalho, conforme Marx desenhou, por meio da teoria da Mais-Valia, o que seria o principal fator de produção da desigualdade social para Marx. Mas este fator é um condicionante do acesso na medida em que produz o que Marx chama de alienação do trabalho. Em outras palavras, a necessidade que o trabalhador tem de dedicar o tempo pleno de sua vida à venda do trabalho bruto (sem conhecimento tecnológico agregado, por exemplo) em troca unicamente da sobrevivência física, destituio de recursos financeiros e de requisitos básicos (informações e habilidades básicas) para lograr o acesso ao capital cultural e social da sociedade. Marx abordou esta questão como fator promotor da desigualdade social. Mas Bourdieu abordou esta questão já numa perspectiva do acesso, o que será explicitado a seguir.

3. O acesso para Bourdieu. Este autor tem um grande mérito: seu vôo próprio construído a partir da essencialidade do pensamento marxista, do positivismo e da teoria da ação social de Weber. Com isso, ele conseguiu superar o vício marxista da vinculação meramente material, sem deixar de 
considerá-la, alertando para os condicionamentos subjetivos, simbólicos, culturais e políticas que fazem parte do processo. Assim ele se refere à questão em diferentes momentos da sua vida e obra, abordando a questão de forma mais absoluta possível. Examinaremos alguns momentos da sua obra:

Em primeiro lugar, devemos considerar a sua célebre produção no livro A Reprodução (com Passeron), ainda com uma forte influência da ortodoxia marxista. Na verdade, a reprodução é resultado de uma pesquisa de Bourdieu intitulada Les Héritiers (Os Herdeiros), com publicação em livro em 1964. Na verdade, com Les Héritiers, Bourdieu inaugura uma longa pesquisa sobre a influência da herança cultural e social no sucesso da individualidade na sociedade e que the chamou a atenção, inicialmente, o caso escolar. Neste caso, Les Héritiers trata da desigualdade escolar, da desigualdade do acesso ao processo escolar que permite às classes dominantes se constituir o monopólio da utilização do sistema escolar e de ver, pelo sucesso profissional e social, a confirmação dos seus dons naturais e sociais; em outras palavras, o sistema escolar é construído para os herdeiros do capital cultural e social, para quem já os têm.

Em segundo lugar, a teoria do habitus como condicionante do acesso. A idéia central que aparece em Habitus está associada à tese dos herdeiros. Habitus, para Bourdieu, seria a apropriação de esquemas cognitivos e avaliativos transmitidos e incorporados de modo pré-reflexivo e automático no ambiente familiar, desde a infância, permitindo a constituição de redes sociais, também pré-reflexivas e automáticas, que cimentam a solidariedade e a identificação por um lado, e a antipatia e o preconceito por outro. De uma forma mais geral, habitus seria certa capacidade do indivíduo adquirida socialmente que lhe permite jogar no bom momento e sem se perguntar se está jogando corretamente, de forma natural, de forma imediata.

Em terceiro lugar, novamente a tese dos herdeiros aparece no que Bourdieu chama de capital cultural e simbólico, cuja tese está bem explicitada no livro A Economia das Trocas Simbólicas (2001). Isto é, os herdeiros recebem de suas famílias um capital cultural. Bourdieu chama de capital cultural o conjunto de conhecimentos e informações que recebem os filhos das classes dominantes de uma forma natural, o que faltam nos estudos para os estudantes dos meios desfavorecidos. Este capital cultural será legitimado, tornado oficial por um diploma escolar.

\section{Conclusão}

É possível hoje a utilização da noção da exclusão social, mas o da inclusão é inconveniente. A conveniência da utilização da noção da exclusão social se restringe à referência de uma problemática social. Os estudos citados no texto de Robert Castel e Serge Paugam indicam que o entendimento de exclusão social hoje diz respeito somente à inquietação geral diante da degradação das estruturas 
da sociedade salarial e as necessidades de se ocupar das vítimas deste processo. Neste caso, a exclusão social não substitui a categoria de análise de classe social e tampouco é incompatível com ela, possibilitando assim o estudo da exclusão social a partir do referencial de classe.

A inadequação da noção de inclusão social se deve a diferentes fatores: Em primeiro lugar em decorrência da transposição automática advinda da exclusão, uma espécie de positivação de uma dada condição social. Em segundo lugar, a partir dos ingredientes históricos que constituem esta palavra, desde o sentido positivo em relação à exclusão aos ingredientes trazidos da sociologia política conservadora, o sentido atribuído a esta noção, tanto na academia quanto pelas chamadas políticas públicas de inclusão, é de uma ação compensatória, sugerindo ser "normal" a desigualdade e a pobreza. Sugere a idéia da existência de um único projeto social, o da classe burguesa e esta classe guarda consigo o direito do controle do acesso aos bens sociais, aos serviços, ao conhecimento socialmente produzido, etc.

A inconveniência da utilização da "inclusão" é referenciada também pelos dados da pesquisa citada neste texto. Os dados da pesquisa referida indicam que a condição da pobreza não se explica mediante parâmetros oficiais, os que trabalham com resultados finais quantitativos e a capacidade individual de sucesso pelo acesso aos bens sociais e serviços, mas esta condição é explicada pelo monopólio das classes sociais dominantes (média e alta) a partir de três principais fatores: 1. Apropriação da riqueza do trabalho, a qual melhor se compreende com a teoria da mais-valia de Marx; 2. Parâmetros avaliativos de normalidade pelos quais criam-se subjetividades valorativas das habilidades e práticas sociais; 3. Exploração das habilidades e práticas sociais a partir da lógica capitalista. Em outras palavras, o que define a condição de pobreza é a falta do acesso. Considerar o acesso e o seu caráter como parâmetro de definição da condição social implica mudar radicalmente o que se pensa a respeito da justificativa da origem e da permanência da condição de pobreza, acentuada na individualidade, como fazem os parâmetros utilizados pelas instituições e os das classes sociais média e alta, para a eficiência das políticas públicas, para a eficácia dos serviços públicos e para o monopólio do acesso aos bens e serviços sociais exercidos pelas classes dominantes. Isto significa dizer que falar de "inclusão" é escamotear o monopólio do acesso aos bens e serviços públicos exercido pelas classe média e alta e a ineficiência das políticas e serviços públicos.

\section{Referências}

BONETI, Lindomar W. Ser ou estar pobre: a construção social da noção da desigualdade. Revista Contex to \& Educação, Ijuí, n. 62, p.115-134, abr./jun. 2001. 
La césure centre/périphérie. In: CHÂTEL, Vivianne; SOULET Marc-Henry. (Org.). Faire face et s'en surtir. Fribourg (Suisse): Editions Universitaires de Fribourg, 2002. 2 v.

L'exclusion sociale en tant que trajectoire de perte d'accès à biens et des services. Bulletin de l'AISLF - Association Internationale des Sociologues de Langue Française, Toulouse-Le, n. 20, 2004.

BOURDIEU, Pierre; PASSERON, Jean-Claude. Les Héritiers. Paris: Minuit, 1964.

Economia das Trocas Simbólicas. São Paulo, SP: Perspectiva, 2001.

; PASSERON, Jean-Claude. A Reprodução: elementos para uma teoria do sistema de ensino. 3. ed. Rio de Janeiro, RJ: F. Alves, 1992.

CASTEL, Robert. Classes sociais, desigualdades sociais, exclusão social. In: CONFERÊNCIA DO COLÓQUIO INTERNACIONAL POLÍTICAS PÚBLICAS, POBREZA E EXCLUSÃO SOCIAL. 2003, Ijuí. Anais... Ijuí: UNIJUÍ, 2003.

De l'indigence à l'éxclusion, la désaffiliation: précarité du travail et vulnerabilité relationnelle. In: Face à l'éxclusion - le modèle françai. Paris: Esprit, 1995.

Les marginaux dans l'histoire. In: L'exclusion, l'Etat du savoir. Paris: La Découvert, 1996.

. As armadilhas da exclusão. In:

Desigualdade e a questão social. São Paulo, SP: Educ. 1997, p. 15-48.

DUBET, François. Les inégalités multipliées ou les épreuves de l'égalité. In: Une Société Monde? Les dynamiques sociales de la mondialisation. Québec: Les presses de lúniversité Laval, 2001.

LENOIR, René. L'Exclus. Paris: Seuil, 1970.

PAUGAM, Serge. Abordagem sociológica da exclusão. In: VÉRAS, Maura Pardini Bicudo et al (Org.) O Debate com Serge Paugam. São Paulo, SP: Educ. 1999.

ROCHER, Guy. Le "polythéisme" des modes d'explication du social. In: CONGRESSO DA ASSOCIAÇÃO INTERNACIONAL DE SOCIÓLOGOS DE LÍNGUA FRANCESA. 2004, Québec. Anais... Quebec: Université Laval, 2004.

ROUSSEAU, Jean-Jacques. Discurso Sobre a Origem e os Fundamentos da Desigualdade entre os Homens. In: Rousseau. São Paulo, SP: Nova Cultural, 1991, p. 201-320 (Coleção os Pensadores). 